\title{
LUPERCIO LEONARDO DE ARGENSOLA CONTINUADOR DE FRANCISCO DE TERRAZAS. NUEVOS DATOS Y DOCUMENTOS
}

Bien poco es, a ciencia cierta, lo que aún hoy en día sabemos sobre la vida y hechos del que fuera el primer poeta mexicano en lengua castellana ${ }^{1}$, el primer lírico renacentista nacido en el propio solar mexicano, y ampliamente conocido en su época como el autor de un quehacer poético nada desdeñable. Efectivamente, Francisco de Terrazas sigue en gran parte abrigando misterios y cobijando sombras, y de su obra sólo nos han llegado fragmentos y piezas sueltas ${ }^{2}$. De aquel ingenio que Cervantes tan elogiosamente evocara en el "Canto de Calíope" de La Galatea (1585) como

\author{
Uno de Nueva España y nuevo Apolo [...] \\ Francisco el uno de Terrazas tiene \\ el nombre acá y allá tan conocido \\ cuya vena caudal nueva Hipocrene \\ ha dado al patrio venturoso nido
}

del autor inspirado y culto de los sonetos petrarquistas incluidos en la colección Flores de varia poesía compilada en México en 1577, del admirador de Ercilla y su seguidor en aquel poema épico que pretende narrar en verso la conquista de México: Nuevo Mundo

1 Joaquín García ICazbalceta, Francisco de Terrazas y otros poetas del siglo $x v i$, Porrúa Turanzas, Madrid, 1962; Francisco de Terrazas, Poesias, ed. Antonio Castro Leal, Porrúa, México, 1941. Varias antologías contemplan con cuidado su obra: Poetas novohispanos. Primer siglo, ed. A. Méndez Planearte, UNAM, México, 1964, y Poesía hispanoamericana colonial. Antología, eds. A. R. de la Campa y Raquel Chang-Rodríguez, Alhambra, Madrid, 1985, por ejemplo.

${ }^{2}$ Nueve sonetos, dos composiciones en décimas que son un diálogo en verso con el dramaturgo Hernán González de Eslava, una epístola amatoria en tercetos, y unos veinte fragmentos del poema épico inconcluso Nuevo Mundo y Conquista. Véase Poesías, ed. Castro Leal. 
y Conquista, del "hombre de calidad, señor de pueblos y gran poeta" que señalara en 1574 el arzobispo y virrey Moya de Contreras, no sabemos ni siquiera la fecha de su muerte, que sus biógrafos marcan siempre con un 1600? interrogativo y dudoso. Aprovechando una documentación que nos salió al paso hace algún tiempo en los archivos, tanto el General de la Nación en México como el General de Indias en Sevilla, intentemos hoy, modestamente, una tímida aproximación a más exactitudes.

$\mathrm{Y}$ así empecemos por el padre del poeta, el conquistador Francisco de Terrazas. Bien sabemos todos que fue compañero de Hernán Cortés, su mayordomo inclusive, y más adelante alcalde de la ciudad de México, como detalladamente testimonian las Actas de Cabildo de la Ciudad de México para los años que van de 1529 hasta su muerte, acaecida en agosto de 1549. Destacan sus nombramientos, como alcalde ordinario el $1^{\circ}$ de enero de 1538 , como tenedor de bienes de difuntos el 4 de enero de 1538, así como las diversas mercedes, solares y derechos varios que le fueron concedidos a lo largo de este año de 1538, su renuncia al cargo de alcalde ordinario el 17 de diciembre de 1538, su nombramiento como sustituto en la diputación el 9 de enero de 1540, su nombramiento de diputado cuando ya era regidor el $1^{\circ}$ de marzo de 1541 , su nuevo nombramiento de alcalde ordinario el $1^{\circ}$ de enero de 1549 , y así hasta su fallecimiento, que consta en acta del 9 de agosto de ese mismo año ${ }^{3}$. No puede dudarse, a la vista de lo que antecede, que se trataba de uno de los conquistadores más favorecidos y de un personaje relevante en la nueva sociedad capitalina que apuntaba en la primera mitad del siglo xvi. Lo confirman además algunos documentos del Archivo General de la Nación de México, como por ejemplo, una cédula real de Carlos V del 6 de julio de 1529 en que, al delimitar los bienes inmuebles de Cortés en la capital mexicana, se ubica con precisión la morada de Terrazas y las de sus vecinos:

[...] otra la calle que vá de la plaza mayor a San Francisco por las espaldas la calle donde están las casas de Rodrigo Rengel e de Pero Sánchez Farfan e de Francisco de Terrazas e de Çamudio lo qual todo los tenéys e poseéys $[\ldots]^{4}$.

${ }^{3}$ Véase la Guía de las Actas de Cabildo de la Ciudad de México. Siglo xvi, Departamento del Distrito Federal y F.C.E., México, 1970, núms. 262, 855, 856, $861,869,875,880,881,912,915,973,1037,1111,1613,1620,1622,1631$, 1641,1663 y 1664 .

${ }^{4}$ Archivo General de la Nación (México), en adelante A.G.N., Ramo 
Apuntemos, de paso, que uno de los vecinos de Francisco de Terrazas padre, el nonagenario conquistador Rodrigo Rengel, era un sonado y conocido malhablado, castigado "por horroroso blasfemo" por la Inquisición y sentenciado nada menos que por el famoso evangelizador franciscano Fray Toribio Motolinía. En efecto, según consta en documentación del A.G.N., el 3 de septiembre de 1527 Rengel fue condenado a pagar 500 pesos de oro, amén de otras penas vejatorias, por Fray Toribio, que se declaraba "Juez Comisario en la dicha causa y pleito", y todo por aquel "horroroso blasfemo" ya aludido 5 . Lo cual, obviamente, no implica que también el padre del poeta adoptara a su vez el recio vocabulario de su vecino e influyera en el entorno léxico que acunara a su hijo. En 1546 y 1548, Francisco de Terrazas padre seguía recibiendo mercedes y dádivas de la hacienda de Cortés, como lo indican dos documentos del A.G.N. que ostentan la firma ológrafa de Terrazas ${ }^{6}$. Si esto, por ahora, no nos habla del hijo poeta, sí nos aclara el ambiente holgado, acomodado y señorial en que transcurrían su infancia y juventud. Desde luego su situación económica y social en la capital novohispana era lo suficientemente afortunada como para permitirle una entrega fácil y libre a las Musas y a las labores líricas, así como un buen acercamiento a la literatura italiana, a la "escuela de Sevilla" o a Camoens, no excluyéndose la posibilidad de un viaje a Europa. Parece natural, además, que con estos antecedentes familiares nuestro poeta considerara empresa poética insoslayable el historiar en verso la conquista de México y enaltecer con el más vivo ardor poético la gesta de un Cortés que tantos beneficios procuraba a su familia.

De hecho, esta tentativa de poema histórico-épico al modo de La Araucana para cantar en versos heroicos la conquista de México, y que conocemos bajo el título de Nuevo Mundo y Conquista (cuyos veinte fragmentos nos dio a conocer Baltasar Dorantes de Ca-

Hospital de Jesús, leg. 285, último cuaderno, fol. $122 \mathrm{r}^{\circ}$.

${ }^{5}$ A.G.N., Serie Inquisición, vol. 1, exp. 10, 24 fols. Otro documento ibid., fol. $54 \mathrm{r}^{\circ}$.

${ }^{6}$ A.G.N., Hospital de Jesús, leg. 257, fol. 1: "Digo yo Francisco de Terrazas ques verdad que rrescebí de vos Andrés Díaz, los pesos. . que son çiento y sesenta y seys pesos y cinco tomines [ . . . y porques verdad que los rrescibí, firmé de mi nombre, ques fecho en 28 de diziembre de 1546 años. Francisco de Terrazas" (firma autógrafa). Ibid, fol. 2: "Digo yo Francisco de Terrazas ques verdad que rrescibí del Sr: Andrés Díaz los pesos de oro [...] y porques verdad que los rrescebí dí este firmado en mi nombre ques fecho a veynte y dos de setiembre de 1548 años. Francisco de Terrazas" (firma autógrafa). 
rranza en la Sumaria relación. . . de 1601-1604), llamaron más de una vez la atención del Consejo de Indias metropolitano, mucho antes de que Dorantes sacara a relucir los textos de Terrazas. Una documentación inédita del Archivo General de Indias de Sevilla así lo atestigua en varias ocasiones. Así es como, ya en 1580 y en carta al Rey del 16 de diciembre, la Audiencia de México daba noticia de esta obra, a la vez que comunicaba ya por esas fechas la muerte del poeta Francisco de Terrazas. Y, por lo que se deduce del estado de sorpresa e impreparación consiguientes de la viuda y de los huérfanos, se trataba de un fallecimiento acaecido en ese mismo año de 1580. Reza así la carta de la Audiencia:

En cumplimiento de lo ordenado por V.Mag. se an buscado en el archivo de esta rreal audiencia papeles tocantes a Historia de las Yndias, y no se a hallado en el ninguno de esta calidad. Francisco de Terrazas, vecino desta çiudad, la comencó a hazer en verso de todas las cosas acaecidas en el descubrimiento y conquista de esta Nueva España y provincia della, y aviendo hecho una buena parte falleció, él cual dexó muger e yjos que entendemos querrán aprovecharse de lo que su padre avía escrito y por estas causas no se ha tratado con ellos $[\ldots]^{7}$.

Acaso fuera para ayudar, o para rendir homenaje a la memoria del poeta fallecido y a su descendencia, que el Cabildo de la Ciudad de México nombró en 1587 a su hijo, también un Francisco de Terrazas, capellán de la ermita de los Remedios, nombramiento que éste finalmente no aceptó ${ }^{8}$. El caso es que la fama del poeta y la admiración por su obra épico-histórica creció al grado de influenciar al Consejo de Indias en la elección para el importante cargo de cronista mayor de indias en 1596. La documentación que se nos ofrece nos informa, efectivamente, que ya en 1591 se andaba proveyendo este cargo por promoción de su titular, el tan conocido cronista Juan López de Velasco, a secretario del rey en la Secretaría de Hacienda, y el primer documento así declara:

1591. - Coronista mayor de las Indias el licenciado Arias de Loyola, en lugar de Juan López de Velasco que pasó a Secretario del Rey, con 400 ducados. A 19 de octubre ${ }^{9}$.

7 Archivo General de Indias (Sevilla), en adelante A.G.I., Sec. Audiencia de México, núm. 70, ramo 1, fol. $1 \mathrm{r}^{\mathrm{o}}$.

8 Guía de las Actas..., núms. 4882, 4886 y 4889.

${ }^{9}$ Colección de documentos inéditos... de Ultramar, CODOUL, $2^{\mathrm{a}}$ serie, vol. 14 (vol. 1 del Índice de papeles del Consejo de Indias), p. 160. 
Ahora bien, no parece ser que el licenciado Arias de Loyola durara mucho tiempo en tal cargo, ni que lo desempeñara con el beneplácito y para satisfacción de todo el mundo. Otro documento del A.G.I. nos aclara que en 1594 se detuvo el salario de Arias por no haber "cumplido con su obligación en lo de la Ystoria". En consulta al rey el 8 de abril de 1594, el Consejo de Indias empezaba por recordar las obligaciones del Cronista:

El licenciado Arias de Loyola, coronista mayor de las Indias, está obligado por cláusula de su título a leer las lecciones de Matemáticas que le ordenare Joan de Herrera, aposentador de Palacio, y a mostrar en este Consejo a fin de cada año algo escripto tocante a la ystoria de las Indias [...],

y se informaba a Felipe II que Arias no había cumplido con este último aspecto de su cometido:

[...] y por no lo aver hecho en lo que toca a la ystoria como quiera que fue proveydo por fin de otubre de noventa y uno, el Receptor le ha detenido la paga del salario $[\ldots]$.

En realidad, Arias de Loyola hallaba muchas dificultades para ordenar, clasificar y aprovechar la documentación proveniente de América y la que le había dejado Juan López de Velasco, embrollándola toda y manifestando pocas dotes para el menester histórico. Lo traducen muy a las claras sus propias excusas y justificaciones, incluidas en el mismo documento y sacadas a relucir por el Consejo de Indias:

[...] el Licenciado Arias a pedido en el Consejo que atento a que su obligación en lo de la Historia se ha de entender quando estén los papeles dispuestos y hecha la elección de ellos neçessaria a la prosecución de lo que está escripto, ya que quando se le huvieran entregado todos los papeles no fuera posible averlos llegado a punto de poder començar a escrivir por ser muchos, muy varios y confusos, y en que es neçesario hazer esquisita diligencia y poner mucho estudio para colegir esta Historia de manera que ajuste a la gravedad de la materia, se le mande pagar el salario sin embargo de la dificultad que pone el Receptor [...], de sus reclamaciones, disponía del material necesario: 
[...] desde a poco que fue proveydo se le entregaron todos los papeles que estavan en poder de Joan López de Velasco pertenecientes a la Historia $[\ldots]^{10}$.

En estas circunstancias parece lógica la decisión de Felipe II de cesar en su cargo de cronista a Arias y de nombrar en su lugar a Pedro Ambrosio de Ondariz, el año siguiente de 1595:

1595. - Coronista mayor Pedro Ambrosio de Ondariz, en lugar del doctor Arias, con el oficio de cosmógrafo, sin obligación de leer la cátedra. -400 ducados. A 16 de septiembre ${ }^{11}$.

En realidad, el rey había decidido volver a juntar en uno solo los cargos de cosmógrafo y de cronista mayor de las Indias, y otorgar el conjunto a quien ya disponía del oficio de cosmógrafo, como nos lo explicará el documento que vamos a utilizar a continuación. Porque el asunto volvería a plantearse al año siguiente por fallecimiento de Pedro Ambrosio de Ondariz, dando lugar a las propuestas del Consejo de Indias que, amén de honrar la memoria de Francisco de Terrazas, hablan muy a las claras de la admiración que se tenía en las altas esferas del poder político hacia el proyectado e inconcluso poema épico del mexicano. Y esto al punto de considerar un nombramiento del peso de cronista mayor de las Indias en la perspectiva de finiquitar la obra de Terrazas y de confiar dicha conclusión y acabamiento nada menos que a uno de los más notables poetas del Siglo de Oro español. Obra también el documento que nos revela esta circunstancia en el Archivo General de Indias; se trata igualmente de una consulta del Consejo de Indias a Felipe II, esta vez el 12 de febrero de $1596^{12}$. Empieza el Consejo recordando al rey los antecedentes inmediatos de la ocupación del cargo de Cronista y sus distintos avatares recientes (fol. $\operatorname{Ir}^{\circ}$ ):

Señor. - Habiendo vacado por los officios de Cosmógrafo y Coronista mayor de las Yndias por la promoción de Juan López de Ve-

${ }^{10}$ A.G.I.. Sec. Indiferente General, núm. 742, ramo 5, doc. 153: "Consejo de Indias. - 8 de abril de 1594. Sobre que el licenciado Arias, Coronista Mayor de las Yndias pide se le pague el salario de su plaça no obstante que hasta agora no aya cumplido con su obligación en lo de la ystoria, y lo que parece".

${ }^{11}$ CODOUL, $2^{\text {a }}$ serie, vol. 14, p. 162.

12 A.G.I., Sec. Indiferente General, núm. 743, ramo 6, 2 fols. $\mathrm{r}^{\circ}-\mathrm{v}^{\circ}$. "En Madrid. - a 12 de hebrero de 1596". 
lasco a la Secretaria de Hazienda, dividió V.Md. los officios entre Pedro Antonio [sic] Ondariz y el doctor Arias de Loyola, con obligación de leer sendas lectiones de matemáticas, y por no se aver aplicado bien el doctor Arias a lo de la Ystoria, volvió V.Md. a juntar ambos officios en Ondariz apartándolo delas lectiones que se encargó al doctor Ferro Fino.

[...] Parece convenir se vuelva a dividir dando dueño a parte a lo de la Ystoria y habiéndose mirado a personas a propósito para ello pareze que lo serán $[\ldots]$.

Y el Consejo de Indias propone una terna a elección de Felipe II, en la que dos nombres son especialmente ilustres. El primero de ellos parece haber sido sólo de "relleno" : "[...] Estevan de Garibay Camalloa que ha muchos años que travaja en Ystorias [...]'". Pero el segundo de los nombres propone todo un programa, por cierto sugerido, apuntado y hasta explícitamente desdibujado, sobre las que habían de ser de ahora en adelante las actividades "poéticas" del cronista de Indias, y ello para continuar y concluir la obra de Terrazas, que se consideraba como un modelo ejemplar. El elegido, Lupercio Leonardo de Argensola, era un escritor de reconocida fama, quien junto con su hermano Bartolomé ilustraba la llamada "escuela aragonesa" en la lírica española del Siglo de Oro, y autor de tragedias que Cervantes estimara en mucho, según lo expresa el cura en el capítulo XLVIII de la primera parte del Quijote:

[...] no os acordáis que ha pocos años que se representaron en España tres tragedias que compuso un famoso poeta destos reinos, las cuales fueron tales, que admiraron y alegraron y suspendieron a todos cuantos las oyeron, [... ] debe de decir vuestra merced por $L a$ Isabela, La Filis y La Alejandra [... ] y mirad si guardaban bien los preceptos del arte, y si por guardarlos dejaron de parecer lo que eran y de agradar a todo el mundo [...].

Y así, atengámonos al documento en que el Consejo de Indias recomienda en 1596 para cronista mayor de Indias, y de este modo, a

[...] Lupercio Leonardo Argensola, hombre docto y leydo en letras humanas, de buen estilo, disposición y lenguaje en escrivir y de quien por estas buenas partes se tiene esperanza que dará muy buena cuenta de la Ystoria, ayudando también a ello averse entendido que es buen poeta, que viene a ser a propósito para acavar la Ystoria de la Nueva 
España que dejó scripta en estancias la mayor parte della Terraças, uno de los primeros descubridores, que dizen es una de las mejores cossas que ay escriptas en nuestra lengua, y dan corregida y llegada a la verdad y sin la licençia de que suelen usar los poetas, que se puede estimar como uno delos graves ystoriadores antiguos $[\ldots]$.

No dejan de llamar la atención varias de las aseveraciones hechas por el Consejo de Indias al sugerir este nombramiento. La primera es la que justifica la elección de Lupercio Leonardo de Argensola por ser "buen poeta", y así digno sucesor de Francisco de Terrazas. Parece como si la urgencia en proseguir con el poema épico del mexicano y concluirlo borrara o pasara a segundo plano las propias necesidades, más estrictas, de la crónica histórica. Más adelante, sorprende también (amén de confundir a Terrazas con su padre el conquistador al calificarlo de "uno de los primeros descubridores") la contradicción al catalogar a Francisco de Terrazas como "uno de los graves ystoriadores antiguos" y reconocerle precisamente como mérito fundamental. . i isu falta de aliento épico y su parca capacidad para cantar la gesta de Cortés con fantasía y ambición de conmover! Su obra se califica como "[...] corregida y llegada a la verdad y sin la licençia de que suelen usar los poetas [...]"'. Bien es verdad que nuestro Terrazas, que Dorantes de Carranza finamente tildaba de "excelentísimo poeta, toscano, latino y castellano", se movía más a gusto en la efusión lírica y en los juegos retóricos del amor platónico, en el manejo de conceptos ingeniosos (aunque a veces un tanto campanudos y engolillados), que en las poderosas y sonoras voces del cantar de gesta. Mas no parece muy claro el proyecto intelectual que aquí animaba al Consejo de Indias. Y así debió de pensarlo el mismo rey. Efectivamente, el tercer personaje presentado en esa misma terna y recomendado también por el Consejo era

Antonio de Herrera que tradujo la Ystoria de Persia y compuso la de Escocia y tradujo lo que scrivieron los católicos yngleses a los franceses, el Açote de los Políticos y El Cerco de París [...].

Y Felipe II escogió a este último personalmente, señalando con su propia mano la decisión en el fol. $2 \mathrm{v}^{\circ}$ del documento:

Lo de Coronista se dé a Antonio de Herrera, dexando lo que tiene por lo del aposento si no lo ha dejado. Yo el Rey. 
Decisión confirmada por el Consejo de Indias mes y medio más tarde, el 28 de marzo de 1596, arreglando los salarios convenientes:

Señor.- En la provisión del officio de Coronista dize V.M. lo siguiente: lo de Coronista se dé a Antonio de Herrera dexando lo que tiene por lo del aposento si no lo a dexado ya [...] una que se le pague el salario que son 300 ducados cada año del officio que tenía de recebir el dinero del arbitrio de las cosas desde fin de noventa y tres acá [ ... y y porque con darle este oficio de Coronista con 400 ducados de salario que tiene $[\ldots]^{13}$,

concluyendo en un arreglo financiero satisfactorio. Y el 15 de mayo el nombramiento de Herrera era oficial:

Coronista mayor Antonio de Herrera por muerte de Pedro Ambrosio. A 15 de mayo ${ }^{14}$.

Llegados aquí cabe una interrogación dictada por la curiosidad y por el afán de imaginar, aunque esté reñido con la explicación científica. ¿Qué habría pasado con la continuación de Nuevo Mundo y Conquista de haber sido nombrado para cronista mayor de Indias el poeta Lupercio Leonardo de Argensola? ¿Acaso el aragonés hubiera podido disponer de los materiales, los recuerdos y las confidencias de conquistadores con que contaba Francisco de Terrazas, mexicano de nacimiento, viviendo en México y de padre personalmente involucrado en la épica proeza? Puede además dudarse de que la vena épica floreciera mejor bajo la pluma de un Lupercio de Argensola, que tampoco destacaba en esta especialidad literaria. A.jeno a la aventura americana, gran poeta pero en quehaceres y temas líricos muy distintos, sus valiosísimas capacidades poéticas se habrían enfrentado aquí con un género que no era el suyo, un mundo que tampoco era el suyo, un pasado con el que poco o nada tenía que ver. El ejercicio poético no hubiera podido ser más gratuito, ni más artificial. Quizá no andara esta vez tan descaminado Felipe II al decidir otros rumbos (y a la vista está la obra magna de Herrera), aunque los motivos del rey no fueran con toda probabilidad estrictamente literarios.

Georges Baudot

Université de Toulouse-Le Mirail

El Colegio de México

13 A.G.I., Indiferente General, núm. 743, ramo 6, doc. 229 bis.

${ }^{14}$ CODOUL, $2^{\mathrm{a}}$ serie, vol. 14 , p. 162. 